\title{
Heterotopic cervical pregnancy management after a high- complexity assisted reproduction procedure
}

\author{
Bernardo Blum Pinto ${ }^{1}$, Tatiana Puga Torres ${ }^{1}$, Medardo Blum Narváez ${ }^{1}$, Xavier Blum Rojas ${ }^{1}$, Ivonne Arce Burgos ${ }^{1}$, \\ Paul Espinoza Constante ${ }^{1}$
}

${ }^{1}$ National Center for Assisted Reproduction - Innaifest.

\begin{abstract}
Heterotopic cervical pregnancies with a viable intrauterine pregnancy are rare, the conservative and prudent management of these cases should be focused on the selective reduction of cervical pregnancies in order to maintain eutopic pregnancy. This paper reports the first case in Ecuador of a heterotopic cervical pregnancy after ICSI procedure and its proper management by ultrasound-guided curettage, allowing the normal development as an intrauterine pregnancy.
\end{abstract}

Keywords: Heterotopic cervical pregnancy, curettage, IVF, ICSI.

\section{CASE DESCRIPTION}

A 35 year-old woman, weighing $56 \mathrm{~kg}$; height $165 \mathrm{~cm}$, with secondary infertility, was submitted to a left hydrosalpinx salpingectomy by laparoscopic procedure, and was later submitted to a high complexity assisted reproduction procedure.

The stimulation protocol consisted of $\mathrm{GnRH}$ agonist with 2700 IU rFSH and a final dose of 10,000 IU hCG. Follicular aspiration was performed on day 12 of the cycle, recruiting 12 oocytes. We proceeded to an in vitro fertilization by intracytoplasmic sperm injection (ICSI). The transfer of two-day cleaved three embryos was performed under ultrasonography. The luteal phase support consisted of $800 \mathrm{mg}$ of vaginal progesterone. At 12 days after the embryo transfer, hCG levels were $810 \mathrm{IU} / \mathrm{ml}$, increasing to $6125 \mathrm{IU} / \mathrm{ml}$ four days later.

Transvaginal ultrasound was performed 27 days after the embryo transfer, confirming a single gestational sac of six weeks and two days in the uterine cavity. Considering the high hCG levels, we suspected of a multiple pregnancy and performed another transvaginal ultrasound one week after, confirming multiple cervix-endometrial pregnancy. Figures 1, 2 and 3 show the evaluation by ultrasound.

Figure 1. Transvaginal two-dimensional ultrasonography showing uterine and cervical sac

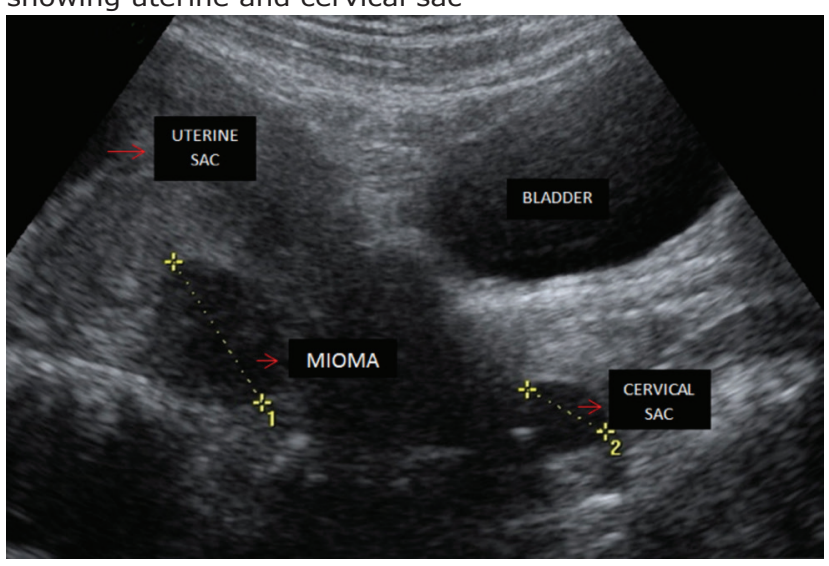

Figure 2. Embryo with heart activity located in the uterus

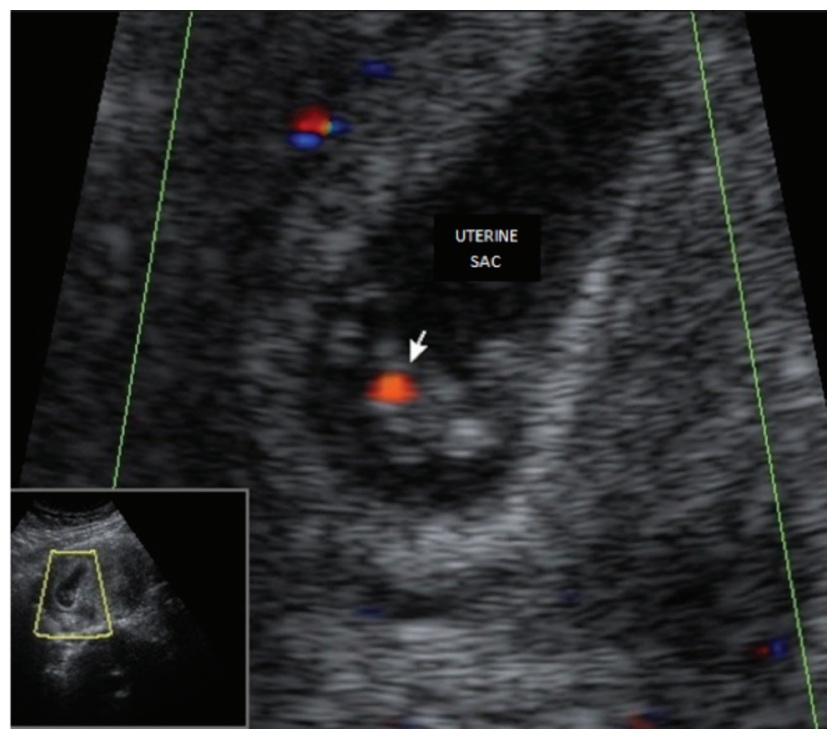

Figure 3. Cross-section showing the location of the pregnancy inside the cervix

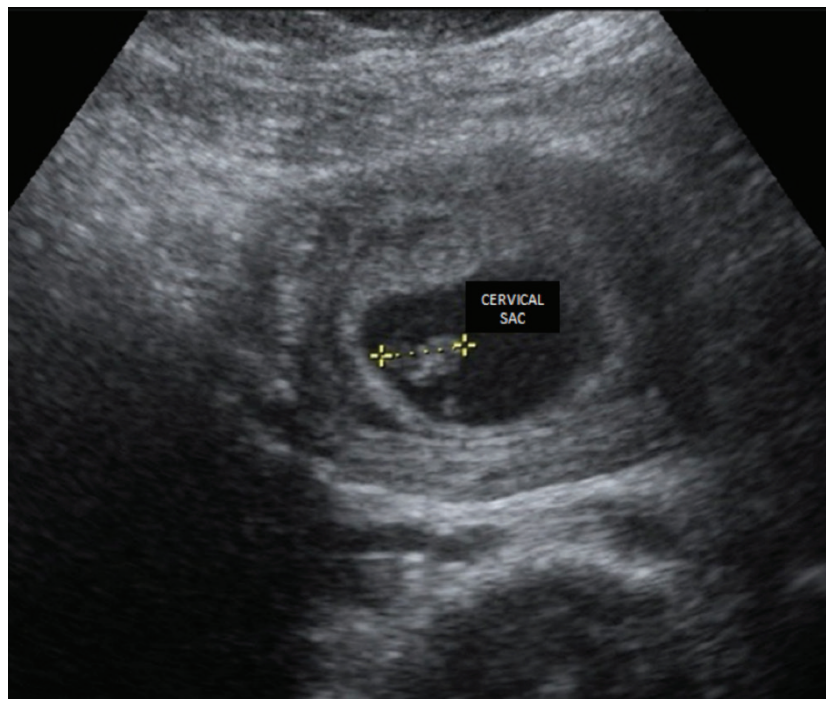

The day after diagnosis, we performed ultrasound-guided cervical pregnancy exeresis under general anesthesia with a full bladder and conventional cervical curettage with normal uterine pregnancy evolution without complications. The pathology evaluation confirmed the presence of POC (Products of Conception).

Uterine pregnancy development was confirmed during the gestation period, obtaining a normal female baby at 39 weeks by segmental caesarean, weighing $3300 \mathrm{~g}$. 


\section{DISCUSSION}

Heterotopic cervical pregnancies are rare, but their incidence is increasing due to in vitro fertilization treatments, this may be the result of factors related to the procedure, such as cervix trauma or embryo reflux in the cervix during transfer (Chen et al., 2001).

Heterotopic pregnancy diagnosis is achieved at an early stage by transvaginal ultrasound, at least in IVF pregnancies, due to increased monitoring (Chen et al., 2001; Jozwiak et al., 2003).

In this case, the presence of heterotopic cervix pregnancy was not detected during the first ultrasound evaluation ( 6 weeks and 2 days), seeing only the uterine pregnancy. Twin pregnancy was suspected due to high hCG levels; therefore, close monitoring was performed, confirming cervix pregnancy at 7 weeks and three days.

Heterotopic cervix pregnancy treatment is performed to try and preserve uterine pregnancy, evacuating the entire cervix pregnancy and avoiding possible bleeding and infection. However, considering the vascularity and the lack of muscle tissue in the cervix region, a catastrophic bleeding may happen and a hysterectomy may be required to save the patients' life (Chen et al., 2001).

In this case it was possible to remove the cervix pregnancy by curettage under ultrasound guidance, without complications. Cervical cerclage was not needed, enabling a term pregnancy without problems.

In Latin America, there are 33 cases of cervix pregnancy published between 1982 and 2002, according to Briceño (2002), with two other cases published between 2005-2015 (Troncoso et al., 2005; Alanis-Fuentes et al., 2015). In Ecuador, the first report of a cervix pregnancy (Rodriguez Espinoza et al., 1995) is from 1995, then six more cases (Morales Zambrano \& Nagua Blanca, 2014) were added. The latter report does not specify the conception type or the treatment followed in each case.

We did not find heterotopic cervix pregnancy reports after assisted reproduction treatment in Latin America. So this would be, at least in Ecuador, the first one.

\section{CONFLICT OF INTERESTS}

No conflict of interest have been declared.

\section{Corresponding author:}

\section{Tatiana Puga Torres}

Centro Nacional de Reproducción Asistida INNAIFEST

Guayaquil, Ecuador

E-mail: fertilidad-innaifest@hotmail.com

\section{REFERENCES}

Alanis-Fuentes J, Brindis-Rodríguez A, Martínez-Arellano M. [Cervical ectopic pregnancy. Hysteroscopy treatment, case report]. J Ginecol Obstet Mex. 2015;83:302-37.

Briceño C. Embarazo cervical. Revista de Obstetricia y Ginecología de Venezuela. 2002; 62(4):261-267.

Chen D, Kligman I, Rosenwaks Z. Heterotopic cervical pregnancy successfully treated with transvaginal ultrasound-guided aspiration and cervical-stay sutures. Fertil Steril. $2001 ; 75: 1030-3$

Faschingbauer F, Mueller A, Voigt F, Beckmann M, Goecke T. Tratment of heterotopic cervical pregnancies. Fertil Steril. $2011 ; 95: 1787 . e 9-13$

Jozwiak E, Ulug U, Akman M, Bahceci M. Successful resection of a heterotopic cervical pregnancy resulting from intracytoplasmic sperm injection. Fertil Steril. 2003; 79:428-30

Majumdar A, Gupta SM, Chawla D. Successful management of post-in-vitro fertilization cervical heterotropic pregnancy. J Hum Reprod Sci. 2009; 2:45-6

Morales Zambrano CG, Nagua Blanca, Diego Raphael. Características Clínicas y Factores de Riesgo del embarazo Ectópico en el Hospital Vicente Corral Moscoso de la Ciudad de Cuenca, Durante el Periodo 2008-2012. Thesis. Universidad de Cuenca. 2014. Available at: http://dspace. ucuenca.edu.ec/handle/123456789/20237.

Prorocic M, Vasiljevic M. Treatment of heterotopic cervical pregnancy after in vitro fertilization-embryo transfers by using transvaginal ultrasound-guided aspiration and instillation of hypertonic solution of sodium chloride. Fertil Steril. 2007; 88:969.e3-5

Rodriguez Espinoza C, Paladines Moran O, Castillo Sanchez J, Leone Stay G, Balseca Sojos R, Salazar Mora B, Rodriguez Jimenez M, Paladines García P. Embarazo ectópico cervical: Reporte del primer caso en Ecuador. Educ. Méd. Contin. 1995; 47:28-32.

Troncoso F, Cardone X, Rondini C, Troncoso C.Embarazo Ectópico Cervical. Diagnóstico y Tratamiento Conservador con Cerclaje Cervical. Rev Chil Obstet Ginecol. 2005; 70: 257-60. 